\title{
EFFECTIVE WAYS TO MANAGE STRESS AND UNMASK THE ABILITIES OF PEOPLE WITH ASPERGER'S SYNDROME
}

\author{
Riichiro Ishida \\ Niigata 953-0042, Japan \\ E-mail: ishida-riichiro@hb.tp1.jp
}

\begin{abstract}
People with Asperger's syndrome often have superior abilities in various fields, including art, natural science, and solving social problems. However, they tend to become stressed easily due to difficulties in relating to others. This stress sometimes prevents them from showing their full potential. Their abilities and tendency to become stressed are similar to those of people with schizoid temperament. Recent evidence has shown that purpose in life (PIL)/ikigai, moderate aerobic exercise, and diet, which are related to each other and to prefrontal lobe function, are effective methods for coping with stress. PIL/ikigai, which is an attitude in which one seeks to establish meaning of life, is developed through positive experiences, such as cordial human relations with suitable role-models, spending time in beautiful natural surroundings, and being moved by people or events. PIL/ikigai for people without schizoid temperament develops through such positive experiences throughout their life. However, PIL/ikigai for people with schizoid temperament/Asperger's syndrome develops through positive experiences during a limited number of life stages: infancy, childhood, and adulthood. Moderate aerobic exercise, such as walking, running, and swimming, were linked to finding food during the evolution of mankind. In turn, our diet supplies nutrients to our organs. Therefore, we propose that providing positive experiences during the critical periods and maturation periods of particular brain regions may influence PIL/ ikigai, which is related to moderate aerobic exercise and diet. This process may help people with Asperger's syndrome to demonstrate their full potential abilities and to contribute to various fields.
\end{abstract}

Key words: Asperger's syndrome, stress, purpose in life/ikigai, moderate aerobic exercise, diet.

\section{Introduction}

Modern society has many challenges to face, including environmental issues, economic problems, and interpersonal conflict. These can lead to stress, which in turn causes mental illness and somatic disease. Additionally, scientists, technicians, and artists all encounter interesting problems in need of solutions. These problems may relate to human happiness, including cognitive and emotional aspects. Hence, fundamental and creative approaches to solve these problems are required.

People with Asperger's syndrome have personality traits similar to those with schizoid temperaments, and these traits are often a mixture of positive and negative (Okada, 2011; Wing, 2010). These traits are thought to be related to genetic factors but also to be influenced by experiences (Okada, 2011; Lamb \& Bornstein, 2011). The incidence of Asperger's syndrome has increased in recent years, and attention has therefore been focused on this disorder (Okada, 2011; Grandin, 2001). People with Asperger's syndrome might be useful to modern society, in terms of providing creative thinkers who are good at solving diverse problems. However, it is important to understand the negative traits and attendant anxiety and irritability during stressful situations that can prevent those with Asperger's syndrome from fulfilling their potential; this could potentially increase happiness for both these people and broader society. Therefore, helping people with Asperger's syndrome 
deal with stress, a process that relates to the autonomic nervous system and endocrine system, may help them to demonstrate their potential ability.

Previous studies have demonstrated effective ways to cope with stress (Frankl, 1972; Kamiya, 2004; Ishida, 2008; Ishida \& Okada, 1997, 1998). One strategy is to develop "purpose in life" (PIL), or "ikigai" in Japanese, which is an attitude in which one seeks to establish meaning in life. Another is moderate aerobic exercise such as walking, endurance running, or swimming. Yet another is management of nutrition by diet.

The term PIL came from European existential philosophy (Kida, 2006) and the term ikigai first appeared in classical Japanese literature (Goto \& Kamada, 1960). People with PIL/ikigai show stable positive cognitive traits and emotions such as ambition, satisfaction, pleasure, comfort, and consideration for others (Kamiya, 2004, Frankl, 1975). Moderate aerobic exercise has been part of life throughout the evolution of mankind, for example in hunting or gathering food in diverse environments. This type of exercise leads to satisfaction, pleasure, and comfort (Ganong, 1997; Howlett et al., 1984; Shen, Chin, Fullerton, Jennings, \& Dart, 1992; Young, 2007). PIL/ikigai and moderate aerobic exercise are concerned with brain function, particularly prefrontal lobe function. This process is concerned with both energy expenditure and secretion of neurotransmitters and hormones (Arnsten \& Pliszka, 2011; Bushman \& Miller, 2007; Goldman-Rakic, 1995). Our diet supplies nutrients, which allow us to maintain energy production (Arnsten \& Pliszka, 2011; Bushman \& Miller, 2007; Goldman-Rakic, 1995). These behaviors (finding PIL/ikigai, moderate aerobic exercise, and diet) are natural, intrinsic, and fundamental behaviors for survival. Successful adaptation to changing environments using these three behaviors allows us to reduce anxiety and confusion and to increase pleasure and comfort (Arnsten \& Pliszka, 2011; Bushman \& Miller, 2007; Goldman-Rakic, 1995; Ishida \& Okada, 1998; Shen et al., 1992; Young, 2007).

Therefore, the present study proposes ways in which to bring out the potential abilities of people with Asperger's syndrome using PIL/ikigai, moderate aerobic exercise, and diet. This process, which involves people being proactive in supporting themselves and improving their ways of coping with stress, has the potential to improve quality of life.

\section{Mechanisms Underlying Asperger's Syndrome}

To gain some insight into Asperger's syndrome, it is important to understand the function of the autonomic nervous system and endocrine system as well as higher brain centers, as these systems help us adapt to changing environments (Smith, Nolen-Hoeksema, Fredrickson, \& Loftus, 2003; Solomon, Berg, \& Martin, 2011). In particular, the prefrontal lobe, which is more evolved in humans than in other mammals (Smith et al., 2003; Solomon et al., 2011), has extensive connections with other areas of the brain (Smith et al., 2003; Solomon et al., 2011). The prefrontal lobe is responsible for functions that are typically "human", such as ambition, cognition, emotion, evaluating information, mental integration, making judgments and decisions, planning for voluntary activity, physical exercise, and organizing responses (Smith et al., 2003; Solomon et al., 2011). These prefrontal lobe functions are mediated by the secretion of neurotransmitters and hormones (Bhatnagar, 2008; Carter, 2010; Ishida \& Okada, 2006; Mehta \& Beer, 2010; Smith et al., 2003; Solomon et al., 2011; Volman, Toni, Verhagen, \& Roelofs, 2011; Young, 2007). Of these neurotransmitters, dopamine is involved in motivation, reward, and reinforcement; noradrenaline influences sleep and wakefulness, attention, and feeding behavior; $\beta$-endorphin is involved in pleasure; oxytocin facilitates the recognition of familiar faces and trust in other people; and serotonin is a major inhibitory neurotransmitter that improves mood and comfort. The steroid hormone testosterone plays an important role in the regulation of social emotional behavior. Attitude, which is based on neuronal networks and is a personal and steady response pattern to our environment, is developed by recurring experiences accompanied by repeated secretion of neurotransmitters and hormones (Augustine, 2008; Carter, 2010). Additionally, each area of the brain has a critical period, during which the neuronal network becomes fixed, and a maturation period, during which the number of synaptic connections increases at a greater rate than at other times, and these periods are important in the development of each function (Atkinson, Atkinson, Smith, Bem, \& Nolen-Hoeksema, 1996; Mesulam, 2002). For example, the critical period of language learning is the first few years of life (Atkinson et al., 1996), and the maturation period 
of the prefrontal lobe is adolescence (Mesulam, 2002). Successful adaptation to a changing environment is associated with positive emotions of pleasure and comfort from these new experiences. In Volume 6, 2013 contrast, unsuccessful adaptation is characterized by negative emotions of anxiety and confusion. The former scenario is related to an optimal balance between the sympathetic nervous system and the parasympathetic nervous system on one hand and endocrine system on the other, i.e., optimal balance of secretion of neurotransmitters and that of hormones (Bhatnagar, 2008; Carter, 2010; Ishida \& Okada, 2006; Mehta \& Beer, 2010; Smith et al., 2003; Solomon et al., 2011; Volman et al., 2011; Young, 2007). The latter scenario is associated with imbalance of these systems.

People with Asperger's syndrome have two types of traits, the expression of which depend on genetic factors and the influence of the environment (Esterberger et al., 2010; Gelder et al., 1999; Lugnegård et al., 2011; Okada, 2011; Perry \& Vaillant, 1989; Sano et al., 1997; Wing, 2010). The positive traits include innovation and perseverance in completing a chosen task or achieving a desired goal (Esterberger et al., 2010; Gelder et al., 1999; Lugnegård et al., 2011; Okada, 2011; Perry \& Vaillant, 1989; Sano et al., 1997; Wing, 2010). The positive traits of people with Asperger's syndrome are similar to those associated with firm PIL/ikigai and are useful in many fields. The negative traits include oversensitivity, unhappiness that is easily provoked, anxiety, a tendency to worry, and a response pattern to other people and events characterized by irritability (Esterberger et al., 2010; Gelder et al., 1999; Lugnegård et al., 2011; Okada, 2011; Perry \& Vaillant, 1989; Sano et al., 1997; Wing, 2010). These negative traits are related to imbalanced secretion of neurotransmitters and hormones, in particular, reduced output of serotonin, gamma-aminobutyric acid (GABA), oxytocin, and higher testosterone levels (Okada, 2011; Takeuchi, 2011). These negative traits sometimes prevent people with Asperger's syndrome from demonstrating their potential abilities (Okada, 2011).

Fortunately, previous studies suggest the possibility of unmasking the potential abilities of those with Asperger's syndrome by repeated positive experiences such as support from others, as such experiences are thought to alter the neuronal network (Okada, 2011; Lamb \& Bornstein, 2011; Solomon et al., 2011).

\section{Unmasking the Potential Ability of People with Asperger's Syndrome}

Evolution, a process that occurs over thousands of years, has provided humans with the ability to adapt to changing environments (Solomon et al., 2011). Previous studies have shown that PIL/ ikigai, moderate aerobic exercise, and appropriate nutrient intake can help people effectively manage stress, including its cognitive and emotional aspects (Arnsten \& Pliszka, 2011; Bushman \& Miller, 2007; Faulconbridge \& Hayes, 2011; Gómez-Pinilla, 2008; Ishida, 2008; Shen et al., 1992; Young, 2007). These strategies could therefore help people with Asperger's syndrome to demonstrate their potential ability. The mechanisms by which PIL/ikigai, moderate aerobic exercise, and appropriate diet might have this effect are discussed.

\section{Mechanisms by which PIL/ikigai Might Benefit Asperger's Syndrome}

$\mathrm{PIL} /$ ikigai may reduce negative emotions such as anxiety and irritability in response to stress, and this is particularly relevant in interpersonal conflict (Ishida, 2008; Ishida \& Okada, 2011). These negative emotions are part of a response pattern in Asperger's syndrome related to schizoid temperament caused by stress (Esterberger et al., 2010; Gelder et al., 1999; Lugnegård et al., 2011; Perry \& Vaillant, 1989; Sano et al., 1997; Wing, 2010). There is some evidence to support the hypothesis that PIL/ikigai can reduce such negative emotions, such as anxiety and interpersonal conflict (Ishida, 2008; Ishida \& Okada, 2011). People with both schizoid temperament and firm PIL/ikigai showed lower state anxiety during stressful interpersonal situations (Ishida, 2008) (Table 1); moreover, those with firm PIL/ikigai showed lower sympathetic activity and confusion during an integration task involving the stressful situation of placing 20 chips labeled with events according to how closely they matched their PIL/ikigai (Ishida \& Okada, 2011). This suggests that firm PIL/ikigai is associated with the natural and effective use of prefrontal lobe functions such as mental integration, thereby helping people cope with stress. Developing a firm PIL/ikigai could accordingly contribute to the unmasking of potential abilities in people with Asperger's syndrome. 
Table 1. Demographic and psychological parameters and Pearson's correlation coefficients for correlations between PIL and state anxiety scores in each temperament group.

\begin{tabular}{ccccccc}
\hline & \multicolumn{3}{c}{ Demographic and psychological parameters } & & \multicolumn{2}{c}{$\begin{array}{c}\text { Pearson's } \\
\text { correlation } \\
\text { coefficient }\end{array}$} \\
\cline { 2 - 6 } & $\begin{array}{c}\text { Number of } \\
\text { subjects } \\
\text { (male : female) }\end{array}$ & Age (years) & PIL test score & $\begin{array}{c}\text { State anxiety } \\
\text { score }\end{array}$ & & \\
\hline Schizoid & $13(5: 8)$ & $31.08 \pm 7.73$ & $51.62 \pm 10.23$ & $38.31 \pm 7.73$ & -0.578 & ** \\
Others & $49(15: 34)$ & $31.22 \pm 13.91$ & $53.67 \pm 9.03$ & $38.86 \pm 7.45$ & -0.037 \\
\hline
\end{tabular}

PIL: purpose in life. ${ }^{* *} p<0.01$. Other temperaments included cyclothymic, viscous, hysterical, asthenic, and combined temperaments. Source: Ishida R. (2008). Acta Medica et Biologica (Niigata), 56 (1), 27-32.

$\mathrm{PIL} /$ ikigai is influenced by the interests that people have and develops from positive experiences (Ishida, 2008). Positive experiences important for building PIL for people with schizoid temperaments similar to Asperger's syndrome include those that happen during limited developmental stages. Examples include devoting time to events during infancy and childhood, being praised by teachers during childhood, being praised by neighbors during infancy, succeeding in attempts during infancy, being moved by people and events during infancy, spending time in beautiful natural surroundings during infancy, childhood, middle adolescence, and at the present time, i.e., adulthood, and having respect for certain people at present, i.e., in adulthood (Ishida, 2008). Such positive experiences for people with other temperaments relate to wider developmental stages compared to people with schizoid temperament/Asperger's syndrome (Ishida, 2008). This suggests that critical periods and maturation periods of particular brain regions may differ between people with schizoid temperament/ Asperger's syndrome and people with other temperaments. It is important that infancy, childhood, and adulthood are common periods influencing PIL/ikigai for all temperaments (Ishida, 2008). This is supported by evidence suggesting that infancy corresponds to the period during which the number of synaptic connections increases rapidly (Carter, 2010), and that synaptic plasticity develops even after adolescence, i.e., during adulthood (Carter, 2010).

It is therefore important that positive experiences within the critical periods and maturation periods of the brain should be provided for people with Asperger's syndrome to unmask their potential ability.

\section{Mechanisms by which Moderate Aerobic Exercise Might Benefit Asperger's Syndrome}

There is also evidence suggesting that moderate aerobic exercise may also decrease anxiety, conflict, and irritable emotional responses for people with Asperger's syndrome (Ganong, 1997; Howlett et al., 1984; Ishida \& Okada, 1997, 1998; Shen et al., 1992; Young, 2007). Among neurotypical people, when those who habitually exercised were compared to those who did not, the former group showed lower sympathetic nervous activity and higher parasympathetic activity on heart rate analysis in the time and frequency domains, both during rest and during loading using a mechanically braked bicycle ergometer (Ishida \& Okada, 1997) (Table 2).

Table 2. Heart rate variability for athletes and non-athletes.

\begin{tabular}{lcc}
\hline \multicolumn{3}{c}{ Mean \pm SD } \\
\hline Number of subjects (male / female) & $\begin{array}{c}\text { Subjects who exercised } \\
\text { regularly }\end{array}$ & $\begin{array}{c}\text { Subjects who did not } \\
\text { exercise regularly }\end{array}$ \\
\hline Age (years) & $8(5 / 3)$ & $16(10 / 6)$ \\
\hline
\end{tabular}




\begin{tabular}{|c|c|c|c|}
\hline & \multicolumn{2}{|c|}{ Mean $\pm S D$} & \\
\hline & $\begin{array}{l}\text { Subjects who exercised } \\
\text { regularly }\end{array}$ & $\begin{array}{l}\text { Subjects who did not } \\
\text { exercise regularly }\end{array}$ & \\
\hline Body weight (kg) & $58.6 \pm 7.9$ & $59.1 \pm 13.0$ & \\
\hline $\mathrm{BMI}\left(\mathrm{kg} / \mathrm{m}^{2}\right)$ & $21.7 \pm 2.6$ & $22.1 \pm 4.0$ & \\
\hline \multicolumn{4}{|l|}{ Heart rate (beats/min) } \\
\hline Mean during 1st rest period & $63.7 \pm 4.0$ & $73.0 \pm 9.1$ & * \\
\hline Mean during loading & $98.0 \pm 7.2$ & $110.0 \pm 13.7$ & * \\
\hline Mean during 2nd rest period & $63.2 \pm 4.9$ & $75.4 \pm 10.0$ & * \\
\hline \multicolumn{4}{|l|}{ CV } \\
\hline Mean during 1st rest period & $3.1 \pm 0.7$ & $2.6 \pm 0.9$ & \\
\hline Mean during loading & $2.9 \pm 0.6$ & $2.1 \pm 0.8$ & * \\
\hline Mean during 2nd resting & $3.1 \pm 0.5$ & $2.8 \pm 1.2$ & \\
\hline Mean of RC during loading & $0.1 \pm 0.1$ & $0.1 \pm 0.0$ & \\
\hline \multicolumn{4}{|l|}{ LF power } \\
\hline Mean during 1st rest period & $0.7 \pm 0.1$ & $0.5 \pm 0.2$ & \\
\hline Mean during loading & $0.4 \pm 0.2$ & $0.6 \pm 0.1$ & * \\
\hline Mean during 2 nd rest period & $0.6 \pm 0.1$ & $0.6 \pm 0.2$ & \\
\hline \multicolumn{4}{|l|}{ HF power } \\
\hline Mean during 1st rest period & $0.3 \pm 0.1$ & $0.4 \pm 0.1$ & \\
\hline Mean during loading & $0.5 \pm 0.2$ & $0.3 \pm 0.1$ & * \\
\hline Mean during 2 nd rest period & $0.3 \pm 0.1$ & $0.3 \pm 0.1$ & \\
\hline
\end{tabular}

Subjects were categorized as those who exercised regularly, i.e., two or more times per week for more than 20 minutes per time, and those who did not exercise regularly, i.e., those who did not meet these exercise criteria. BMI: body mass index, SD: standard deviation, CV: coefficient of variation, RC: regression coefficient, LF: low frequency, HF: high frequency, ${ }^{*} p<0.05$. Loading was performed by exercising on a mechanically braked bicycle ergometer at $50 \mathrm{rpm}$ and $40 \mathrm{~W}$ for 10 minutes. Before loading, participants had a supine rest period of 2 minutes. An electrocardiogram (ECG) was recorded and analyzed performed at each session. Source: Ishida, R., \& Okada, M. (1997). The Japanese Journal of Clinical Pathology, 45 (7), 685-688.

Moreover, endurance running increases levels of serotonin (Young, 2007) and $\beta$-endorphin (Ganong, 1997; Howlett et al., 1984; Shen et al., 1992). These findings suggest that moderate aerobic exercise, which includes walking, running, and swimming, may decrease anxiety and irritability and thus help people with Asperger's syndrome to demonstrate their ability. Excessive intensity of aerobic exercise, however, causes overproduction of reactive oxygen species, damaging cells and the genetic material within them (Sahlin et al., 2010), as occurs in sports anemia, in which hemoglobin level is reduced (McArdle, Katch, \& Katch, 1996). Additionally, improvement in autonomic nervous system function depends on not only training time but also on energy expenditure during the training period (Ishida \& Okada, 2001). This suggests that, over thousands of years, our systems have evolved to respond best to moderate intensity exercise, such as walking, running, and swimming, similar to activities involved in hunting and gathering food in diverse environments. It seems that an appropriate exercise protocol that takes into account age, sex, and other physical conditions should be implemented, not only for people with Asperger's syndrome but for everyone in modern society (McArdle et al., 1996). 
OF PSYCHOLOGY

IN THE $21^{\text {st }}$ CENTURY Volume 6, 2013

Mechanism by which Diet Might Benefit Asperger's Syndrome

Eating food naturally provides satisfaction, pleasure, and comfort. Moreover, dietary nutrients are necessary to maintain brain function (Gómez-Pinilla, 2008). Indeed, nutrients influence cognition, emotion, energy supply, and synthesis of neurotransmitters and hormones (Gómez-Pinilla, 2008). Achieving the pleasure and comfort that comes from having a healthy brain requires the following six basic nutrients: glucose, amino acids, essential fatty acids, phospholipids, vitamins, and minerals (Ikuta, 2010). Children with autism spectrum disorders were more likely to eat the same foods regularly and have more food preferences compared to typically developing peers (Cermak, Curtin, \& Bandini, 2010). Hence, an appropriate diet with consideration of nutrient content is important to maintain a healthy life, not only for people with Asperger's syndrome but also for everyone in modern society.

\section{Limitations and Future Study}

The proposals in this paper are not based on evidence but are instead hypothetical. This research is based on data from a limited number of publications selected by the author. The publications were selected based on their relevance according to the author's daily experiences and previous research. However, many other significant publications could be gathered from databases or the internet for statistical analysis. This process may identify current trends in the field of research on Asperger's syndrome, leading to more significant proposals in the future. Further research into the brain including aspects of its evolution and function is required to investigate these hypotheses. Moreover, the broader field of science, as well as those of philosophy and literature, could be a source of inspiration to help people with Asperger's syndrome. Further studies across such fields should therefore be performed to help those with Asperger's syndrome to fully realize their potential.

\section{Conclusions}

People with Asperger's syndrome have positive traits involving creative and persistent thinking, and these potential abilities could be harnessed to allow these individuals to innovate in various fields. However, the negative traits of this syndrome include a tendency to experience anxiety and problems with interpersonal relationships, leading to conflict and isolation. These negative traits often prevent those with Asperger's syndrome from fulfilling their potential. PIL/ ikigai, moderate aerobic exercise, and diet are related to each other, and are effective methods of coping with the cognitive and emotional aspects of stress, i.e., they increase satisfaction, pleasure, and comfort, and decrease anxiety and conflict. The mechanism by which this happens involves the autonomic system and the endocrine system via secretion of neurotransmitters and hormones. In neurotypical people, PIL/ikigai develops from positive experiences such as loving human relationships, spending time in beautiful natural surroundings including playing and exercising, being moved by people and events, and succeeding in meeting challenging targets. However, in people with schizoid temperament (which is associated with similar traits to Asperger's syndrome), PIL/ikigai is fostered in more limited developmental stages: infancy, childhood, and adulthood.

Therefore, we propose that providing positive experiences with consideration of critical periods and maturation periods of various brain regions and functions may influence PIL/ikigai, which also relates to moderate aerobic exercise and diet. This process may help to unmask the full potential abilities of people with Asperger's syndrome, allowing them to contribute to various fields.

\section{References}

Arnsten, A.F., \& Pliszka, S.R. (2011). Catecholamine influences on prefrontal cortical function: Relevance to treatment of attention deflect hyperactivity disorder and related disorders. Pharmacology, Biochemistry, and Behavior, 99 (2), 211-216. 
Augustine, G.J. (2008). Neural signalling. In D. Purves, G.J. Augustine, D.F. Lawrence, C.K. Anthony-Samuel LaMantia, J.O. McNamara, \& S.M. Williams (Eds.), Neuroscience. Sunderland: Sinauer Associate, Inc..

Bhatnagar, S. (2008). Neuroscience for the study of communicative disorders. Baltimore, MD: Lippincott Williams \& Wilkins.

Bushman, T.J., \& Miller, E.K. (2007). Top-down versus bottom-up control of attention in the prefrontal and posterior parietal cortices. Science, 315, 1860-1862.

Carter, R. (2010). Mapping the brain. London: Phoenix.

Cermak, S.A., Curtin, C., \& Bandini, L.G. (2010). Food selectivity and sensory sensitivity in children with autism spectrum disorders. Journal of the American Dietetic Association, 110 (2), 238-246.

Esterberger, M.L., Goulding, S.M., \& Walker, E.F. (2010). A personality disorders: Schizotypal, schizoid and paranoid personality disorders in childhood and adolescence. Journal of Psychopathology and Behavioral Assessment, 32 (4), 515-528.

Faulconbridge, L.F., \& Hayes, M.R. (2011). Regulation of energy balance and body weight by the brain: A distributed system prone to disruption. The Psychiatric Clinics of North America, 34 (4), 733-745.

Frankl, V.E. (1972). The meaning of meaningless: A challenge to psychotherapy. American Journal of Psychoanalysis, 32, 85-89.

Frankl, V.E. (1975). Der Unbedingte Mensch. Bern; Verlag Hans Huber.

Ganong, W.F. (1997). Review of medical physiology (18th Ed.). Stamford: Appleton and Lange.

Gelder, M., Mayou, R., \& Geddes, J. (Eds). (1999). Psychiatry. Oxford,: Oxford University Press.

Goldman-Rakic, P.S. (1995). Cellular basis of working memory. Neuron, 14, 477-485.

Gómez-Pinilla, F. (2008). Brain foods: The effects of nutrients on brain function. Nature reviews. Neuroscience, 9 (7), 568-578.

Goto, T., \& Kamada, K. (1960). Taiheiki. Tokyo: Iwanami-Shoten.

Grandin, T. (2002). The world needs people with Asperger's syndrome. Cerebrum.

Howlett, T.A., Tomlin, S., Ngahfoong, L., Rees, L.H., Bullen, B.A., Skrinar, G.S., McArthur, J.W. (1984). Release of $\beta$-endorphin and met-enkephalin during exercise in normal woman: Response to training. British Medical Journal, 288, 1950-1952.

Ikuta, S. (2010). Tabemono-wo-kaereba-noh-ga-kawaru. Tokyo: PHP-Shinsho.

Ishida, R. (2008). Correlation between Purpose in Life (ikigai) and state anxiety in schizoid temperament with consideration of early life, youth, and adulthood experiences. Acta Medica et Biologica (Niigata), $56(1), 27-32$.

Ishida, R., \& Okada, M. (1997). Spectrum analysis of heart rate variability for the assessment of training effects. The Japanese Journal of Clinical Pathology, 45 (7), 685-688.

Ishida, R., \& Okada, M. (1998). Effects of physical training on heart rate variability and blood cell counts in healthy adults. Acta Medica et Biologica (Niigata), 46 (4), 139-146.

Ishida, R., \& Okada, M. (2001). Analysis of correlation between physical training and autonomic function by using multivariate analysis: Establishing an indicator of health. The Japanese Journal of Clinical Pathology, 49 (11), 1162-1165.

Ishida, R., \& Okada, M. (2006). Effects of a firm purpose in life on anxiety and sympathetic nervous activity caused by emotional stress: assessment by psycho-physiological method. Stress Health, 22, 275-281.

Ishida, R., \& Okada, M. (2011). Factors influencing the development of "Purpose in Life" and its relationship to coping with mental stress. Psychology, 2 (1), 29-34.

Kamiya, M. (2004). Ikigai-ni-tsuite. Tokyo: Misuzu-Shobo.

Kida, G. (2006). Gendai-shiso. Tokyo: Shin-Shokan.

Lamb, M.E., \& Bornstein, M.H. (2011). Social and personality development: An introduction and overview. In M.E. Lamb, \& M.H. Bornstein (Eds.), Social and personality development. New York: Psychology Press. 
OF PSYCHOLOGY

IN THE $21^{\text {st }}$ CENTURY Volume 6, 2013

36

Lugnegård, T., Hallerbäck, M.U., \& Gillberg, C. (2011). Personality disorders and spectrum disorders: what are the connections? Comprehensive Psychiatry. (in press)

McArdle, W.D., Katch, F.I., \& Katch, V.L. (1996). Exercise physiology (4th Ed.). Baltimore: William \& Wilkins.

Mehta, P.H., \& Beer, J. (2010). Neural mechanism of the testosterone-aggression relation: The role of orbitofrontal cortex. Journal of Cognitive Neuroscience, 22, 2357-2368.

Mesulam, M. Marsel. (2002). The human frontal lobes: transcending the default mode through contingent encoding. In D.T. Stuss, \& TR.T. Knight. (Eds.), Principals of frontal lobe function. Oxford: Oxford University Press, Inc.

Okada, T. (2011). Asperger syndrome. Tokyo: Gento-Sha.

Perry, J.C., \& Vaillant, G.E. (1989). Personality disorders. In H.I. Kalpan, A.M. Freedman, \& B.J. Sadock (Eds.). Comprehensive textbook of psychiatry/V (pp. 1352-1387). Baltimore-London: Williams \& Wilkins Company.

Sahlin, K., Shabalina, I.G., Mattsson, C.M., Bakkman, L., Femström, M., Rozhdestvenskaya, Z., Enqvist, J.K., Nedergaard, J., Ekblom, B., \& Tonkonogi, M. (2010). Ultraendurance exercise increases the production of reactive oxygen species in insolated mitochondria from human skeletal muscle. Journal of Applied Physiology, 108 (4), 780-787.

Sano, K., Makita, H., \& Sakabe, S (Eds.). (1997). Seiken-shiki Personality Inventory Manual. Tokyo: KanekoShobo.

Shen, A., Chin, J., Fullerton, M., Jennings, G., \& Dart A. (1992). Increased in plasma $\beta$-endorphin concentrations during exercise do not contribute to increase in heart rate following autonomic blockade in man. British Journal of Clinical Pharmacology, 33, 89-92.

Smith, E.E., Nolen-Hoeksema, S., Fredrickson, B.L., \& Loftus, G.R. (2003). Atkinson \& Hilgard's Introduction to psychology (14th Ed.). Belmont: Wadsworth/Thomson Learning.

Solomon, E.P., Berg, L.R., \& Martin, D.W. (2011). Biology. Belmont: Brooks/Cole.

Takeuchi, Y. (2011). Serotonergic neurotransmitters in autism spectrum disorders. In V. Eapen (Ed.). Autism-a neurodevelopment journey from genes to behavior. INTECH. Retrieved April 1, 2013, from http://www. intechopen.

Volman, I., Toni, I., Verhagen, L., \& Roelofs, K. (2011). Endogenous testosterone modulates prefrontalamygdala connectivity during social emotional behavior. Cerebral Cortex (New York, N.Y. : 1991), 21, 2282-2290.

Wing, L. (2010). Asperger syndrome: a clinical account. Psychological Medicine, 11, 115-129.

Young, S.N. (2007). How to increase serotonin in the human brain without drugs. Journal of Psychiatry \& Neuroscience: JPN, 32 (6), 394-39.

Advised by Serhiy Boltivets, Grigory Kostyuk Psychological Institute of the Ukrainian National Academy of Pedagogical Sciences, Ukraine

Received: April 10, 2013

Accepted: June 11, 2013 